\title{
Do Campaign Donors Influence Polarization? Evidence from Public Financing in the American States*
}

\author{
Jeffrey J. Harden ${ }^{\dagger} \quad$ Justin H. Kirkland ${ }^{\ddagger}$ \\ January 29, 2015
}

Forthcoming, Legislative Studies Quarterly

\begin{abstract}
Does the source of campaign funds influence legislative polarization? We develop competing theoretical expectations regarding the effects of publicly-financed elections on legislative voting behavior. To test these expectations, we leverage a natural experiment in the New Jersey Assembly in which public financing was made available to a subset of members. We find that public financing exerts substantively negligible effects on roll call voting. We then find a similar result in an examination of state legislatures. We conclude that, counter to the logic of the U.S. Supreme Court, pundits, and reformers, the source of campaign funds exerts minimal influence on polarization.
\end{abstract}

${ }^{*}$ This article was previously presented at the 2014 State Politics and Policy Conference, Bloomington, IN. Complete replication data and the appendix are available at the authors' websites. For helpful feedback we thank Scott Adler, Kevin Banda, Dan Biggers, Nate Birkhead, John Griffin, Jens Hainmueller, Luke Keele, Ryan Kennedy, Ray La Raja, Carlisle Rainey, Steve Rogers, Anand Sokhey, Jason Windett, and Chris Witko. All errors are our own.

$\dagger$ Assistant Professor, Department of Political Science, University of Colorado Boulder, 416 Fleming, UCB 333, Boulder, CO 80309, jeffrey.harden@ colorado.edu.

$\ddagger$ Assistant Professor, Department of Political Science, University of Houston, 434 Phillip Guthrie Hoffman Hall, Houston, TX 77204, jhkirkland@uh.edu. 
In its controversial Buckley v. Valeo decision in 1976, the U.S. Supreme Court ruled that money constitutes protected political speech under certain circumstances. By striking down provisions of the Federal Election Campaign Act of 1971—which limited campaign and independent expenditures-Buckley v. Valeo has become a judicial cornerstone for several subsequent decisions that have eliminated efforts to dampen the effects of money in elections (e.g., Davis v. Federal Election Commission [2008], Citizens United v. Federal Election Commission [2010], and Arizona Free Enterprise Club's Freedom Club PAC v. Bennett [2011]). In all of these instances, the Supreme Court held that the act of donating money is a protected form of speech and that using public funds to equalize spending across candidates dilutes the political speech of those providing private donations. That is, in the Court's view, donating to campaigns is a form of political participation that is valuable to the public precisely because it can influence public officials' behavior. The Court's logic leads to a critical question for scholars of representation: do campaign donations actually alter the behavior of elected officials?

By stating that campaign donations are a form of protected speech, the Court's recent decisions indicate that the answer to this question is "yes." Others have made similar observations, with a particular emphasis on whether campaign contributions influence the ideological extremity of legislators' voting behavior. Many observers state that private donors may be ideologically motivated and/or play a role in driving polarization in Congress and state legislatures, including academic researchers (e.g., La Raja and Wiltse 2012; McCarty 2014; Hall 2014, but see Wawro 2001; Masket and Miller 2015), editorial columnists (Krugman 2002; Klein 2013), and advocacy groups (Common Cause 2014). Even President Obama, in response to the Citizens United case, stated that "ideological extremists who have a big bankroll... can entirely skew our politics" (Blumenthal 2013). However, empirically isolating the causal effect of campaign donations on ideological extremity has proven difficult because of the myriad of other factors that contribute to polarization as well as the possibility that the causal arrow may actually point in the opposite direction (McCarty, Poole, and Rosenthal 2006).

In this research, we consider whether the claim that private donors facilitate legislative polar- 
ization stands up to empirical scrutiny by examining the effect of eliminating their donations. We use novel evidence and causal inference methods to estimate the impact of publicly-financed campaigns on ideological extremity at the individual legislator level (roll call voting) and on legislative party polarization. We first develop a series of theoretical expectations regarding the influence of donations — and by extension, removing them via public funding—on legislators' voting behavior. We posit that the introduction of public financing may either moderate, polarize, or exert negligible effects on the ideological extremity of votes in committee and at roll call. We then test these predictions in two analyses from the American states.

First, we leverage a natural experiment in public financing provided by the New Jersey Fair and Clean Elections Pilot Project. The program instituted public financing in state legislative elections for a subset of the New Jersey Assembly in 2005 and 2007. While the program did not produce a large sample of data, it did provide a rare and valuable opportunity to observe the behavior of legislators in the same chamber under different electoral rules. We utilize synthetic case control to generate predictions of what the publicly-financed legislators' voting behavior would have looked like had they not used public funds. We then compare those predictions to the legislators' actual voting behavior after public financing. We find virtually no ideological adaptation by individual legislators to the advent of publicly-financed legislative elections. We then extend this individuallevel analysis to a similar design in which we examine the entire state legislatures in Arizona and Maine before and after public financing. Our results again indicate that the effect of publiclyfinanced elections on legislative behavior is substantively negligible.

Overall, we conclude that there is strong evidence that legislators do not respond to the source of campaign funding through the ideological extremity of their voting behavior. This conclusion holds at both the committee and floor vote stages of the legislative process. Campaign donations may represent some form of political participation or speech, but that speech appears largely ineffective in influencing votes in state legislatures. In short, our evidence runs counter to the conventional wisdom cited above. While public financing programs may be normatively beneficial for increasing electoral competition and/or reducing corruption in government, they do not appear to 
alter the voting behavior of legislators.

\section{Campaign Finance and the Role of Money in Politics}

The role of money in politics has long been a topic of considerable scholarly and normative interest. From Schattschneider (1960) to recent work on economic and political inequality (e.g., Bartels 2008; Gilens 2012), scholars have made the case that money is a necessary (though not always sufficient) prerequisite for political influence. For example, money impacts the rate at which citizens participate in politics (Schlozman, Verba, and Brady 2012), the emergence of challengers to legislative office (Hogan 2001), interest groups' strategies for influencing election outcomes (Hogan 2005), direct democracy campaigns (Stratmann 2006), and other political outcomes. There is also some evidence that money contributed to campaigns influences legislative behavior, though this contention is not without its detractors (cf. Wawro 2001; Ansolabehere, de Figueiredo, and Snyder 2003; Stratmann 2005; La Raja 2008). Overall, the question of whether money is too influential in American politics has produced considerable debate in recent decades.

A subset of this literature looks to the American states to understand the role of various institutions that govern the financing of election campaigns. For example, this work examines whether limits on campaign donations influence legislative behavior as well as citizen perceptions of politics. Hamm and Hogan (2008) find that low contribution limits for legislative campaigns increase the probability of a challenger emerging to test an incumbent. Stratmann and Aparicio-Castillo (2006) show that campaign finance restrictions contribute to closer margins of victory in state legislative elections. However, these apparent normative benefits of campaign finance reform are countered by Primo and Milyo's (2006) finding that such restrictions do not consistently lead to a more politically efficacious population of voters. Thus, even limits on donors' influence may not be enough to convince the public that politicians' votes are not bought and sold.

Other work examines the effects of the "clean elections" movement that takes nearly all campaign money out of the hands of private donors by making public funds available. Malhotra (2008) uses data from Arizona and Maine_-states that adopted full public financing programs for legislative elections in 2000 - to assess electoral competitiveness. He finds that in both states com- 
petitiveness increased following the implementation of public funding of campaigns. These laws have also been shown to increase the number of candidates for office (Daniel 2001) and reduce the amount of time candidates must spend raising money (Francia and Herrnson 2003).

Competitiveness, the candidate pool, and time spent fundraising are all critical factors in understanding the role of money in electoral politics. However, to this point scholarly literature on public funding of campaigns has largely ignored its role in shaping ideological extremity in voting behavior, both at the individual level and through polarization between the parties (Mayer 2013, but see Hall 2014; Masket and Miller 2015). There is some evidence supporting the view held by media observers that campaign contributions and contribution limits can facilitate polarization (e.g., McCarty, Poole, and Rosenthal 2006; La Raja 2008; Hall 2014). But scholars do not know much about how removing the influence of private donors via public funding impacts extremity. This is a critical question because of the widely-held belief that extreme politics and polarization between the parties is problematic for American democracy. Assessing whether legislators' behavior in office is different when taxpayers pay for their campaigns is critical for understanding the normative implications of money in a representative democracy.

\section{Public Financing and Legislative Behavior}

The primary assumption motivating our theoretical framework is the notion that donors are, on average, more ideologically extreme than the general population. ${ }^{1}$ Past literature provides strong support for this assumption (e.g., Ensley 2009; Bafumi and Herron 2010; Stone and Simas 2010). Furthermore, in the appendix we provide our own empirical confirmation of it with survey data from the 2006, 2008, and 2010 Cooperative Congressional Election Studies. Because extreme citizens are systematically more likely to donate, several potential pathways for private donations to influence legislative polarization exist.

\footnotetext{
${ }^{1}$ Some donors may not be strictly ideologically motivated in their giving, which is why we only claim that donors are more ideological on average compared to non-donors. For example, some interest groups may give for nonideological reasons. However, even non-ideological donors-who give only to influence a narrow set of policies that will benefit them - still attempt to move policy away from what the average constituent would want (Hall and Wayman 1990).
} 


\subsection{The Moderating Hypothesis}

Our first hypotheses are derived from an investment model of campaign donations. Under such a model, campaign donations are investments by donors in legislators' future behavior, and donors expect some sort of a return on their investment. Forward-looking legislators, who feel compelled to gather donations to support their re-election interests, vote on legislation in ways that satisfy past donors and encourage repeat donations to fund their campaigns. That is, legislators weigh the preferences of voters in their districts and the preferences of donors in deciding how to vote at roll call (see Miler 2010). Because potential donors are more ideologically extreme than potential voters, this desire for private donations causes legislators to vote in more ideologically extreme ways on legislation. This perspective is supported by the investment model from Powell (2012), who assumes and finds support for the notion that legislators who raise significant private campaign donations are increasingly likely to adopt positions less popular with their constituents. That is, legislators seek out funds and spend time fundraising in order to win elections, but in obtaining those funds, legislators enter into a tacit agreement with donors to support the donors' preferences over those of the general constituency. ${ }^{2}$

Our first hypothesis posits that this increased representational deficit extends both to legislators' pre-floor behaviors, such as committee votes, as well as their floor voting patterns. ${ }^{3}$ Legislators who hope to satisfy previous donors and encourage new donors support the advancement of legislation their donors prefer throughout the legislative process both as an effort to change policy and to provide themselves with opportunities for position taking on that more extreme legislation. ${ }^{4}$ However, public financing eliminates legislators' need to use private donors as their primary source of campaign funding. Consequently, they are freed from the pressure to represent donors more than

\footnotetext{
${ }^{2}$ Of course, publicly-financed candidates often continue fundraising for their caucuses or parties (Powell 2012). However, in no longer fundraising for themselves, these legislators' direct obligations to private donors is eliminated.

${ }^{3}$ Throughout our theoretical development, we distinguish between the effects of public financing on committee voting and floor voting to leverage the different effects donations may have on pre-floor versus floor behavior (Hall and Wayman 1990; Powell 2012).

${ }^{4}$ It is important to note that individual donors—not interest organizations-are the largest source of campaign funds (Ansolabehere, de Figueiredo, and Snyder 2003). The analysis in the appendix clearly demonstrates that these donors are typically more extreme than non-donors. Thus, legislators courting individual donations have incentives to cast extreme votes.
} 
voters in general. This encourages legislators to vote in less ideologically extreme ways both in committee and on the floor of the chamber.

Moderating Hypothesis: (a) Committee Voting: Public financing of legislative elections reduces the ideological extremity of individual legislators' voting behavior in committees.

(b) Floor Voting: Public financing of legislative elections reduces the ideological extremity of individual legislators' roll call behavior on the floor of the chamber. ${ }^{5}$

\subsection{The Flanking Hypothesis}

It is also possible that public financing has the opposite effect on ideological extremity. One of the primary purposes of public financing is to encourage candidate emergence and electoral competition (see Mayer 2013). Public financing lowers the typical barriers that deny many potential candidates a chance at running for office. With public money, candidates do not need to rely as heavily on support from private donors, political action committees, or political parties. As a result, it is easier for an ideologically extreme candidate-someone who the party establishment would not likely support due to low electoral viability - to enter a race. Extreme candidates have strong motivation to run, but under normal circumstances may lack resources to establish themselves. Public financing opens the door for such candidates. Additionally, publicly-financed elections eliminate incumbent legislators' ability to build significant "war chests" with their own fundraising. Since these war chests are primarily tools to scare off challengers, public financing weakens one of the primary sources of the incumbency advantage (Box-Steffensmeier 1996; Hogan 2001). ${ }^{6}$

This could be problematic for incumbents. The increased threat of challenger entry, particularly from the ideological wings of their parties, may force incumbent legislators themselves to

\footnotetext{
${ }^{5}$ While a moderating effect of public financing is a clear logical extension of prior works on campaign donations, this would be an important hypothesis to test even if it were not. A large portion of the popular outcry around campaign donations centers on the idea that wealthy individual donors polarize legislative behavior. Much of the motivation for campaign finance reform emerges from a concern that extreme donors are "buying" legislators' votes. Thus, even if it were not an extension of existing literature, testing this hypothesis would be an important validation of the intended effects of campaign finance reform.

${ }^{6}$ There is an implicit assumption here that parties prefer to advance the causes for candidates who are proximate to the median voter and that such candidates are likely to win elections. This implies that the ideological space most likely to see new candidates enter electoral competition would be the extreme ideological wings.
} 
move to the extremes of the ideological spectrum. In other words, to ward off potential challengers that would be encouraged to run by public financing, forward-looking legislators may begin to vote more extremely on legislation so they are not "outflanked" by extremists. ${ }^{7}$ This implies that legislators may vote more extremely in committee in order to provide better opportunities for extreme position taking on the floor, and ultimately vote more extremely on floor roll calls themselves. Thus, under this process we expect the level playing field that comes from the use of public financing to lead legislators to polarize as they attempt to ward off extreme challenges. Some evidence on the campaign effects of public financing supports this perspective. Hall (2014) uses a regression discontinuity approach to provide evidence that public financing encourages more extreme candidates to run for office. If incumbents hope to ward off these challengers, their individual behavior should adapt to public financing by becoming more extreme themselves.

Flanking Hypothesis: (a) Committee Voting: Public financing of legislative elections increases the ideological extremity of individual legislators' voting behavior in committees.

(b) Floor Voting: Public financing of legislative elections increases the ideological extremity of individual legislators' roll call behavior on the floor of the chamber.

\subsection{The Strategic Donor Hypothesis}

The investment model of private campaign donations makes the same predictions for legislative behavior at the committee and floor stages and suggests that donors use campaign dollars to change legislative behavior. However, a vast literature on the behavior of political donors suggests that donors are strategic in their choices about to whom they donate (e.g., Hall and Wayman 1990; Stratmann 1992). Much of this literature claims that donors provide funds to legislators who already support the position of the donor prior to the actual donation as an effort to subsidize legislative attention and access, particularly at the committee stage (Hall and Wayman 1990). Rather

\footnotetext{
${ }^{7}$ It may seem odd that we suggest that incumbents respond to challengers who may otherwise be non-viable. After all, if these potential challengers were so formidable, they would run under normal circumstances. We assume that all legislators would prefer to run unopposed than face any type of challenge, and so incumbents are likely to attempt to ward off even non-viable opponents. For example, Eric Cantor (R-VA) faced Dave Brat in the 2014 Virginia primary when Brat was not considered a particularly large threat to the House majority leader. Brat, of course, went on to defeat Cantor. We assume that in hindsight, Cantor would have preferred to ward off this non-viable candidate by preemptively flanking him.
} 
than attempting to change a legislator's mind about an issue, campaign donations are meant to focus a legislator's attention and effort on a subset of issues prior to legislative activity on the floor.

The set of issues that legislators may consider in any session is enormous, so donors use campaign donations to encourage legislators to behave in biased ways during agenda development. When legislators respond to these strategic and ideologically extreme donors, they do so by advancing a legislative agenda out of committee that is more extreme than the preferences of the general constituency. Strategic donors use their influence to mobilize bias in committees and are satisfied with the amplified attention to the issues they prefer. This allows legislators to vote however they wish on the floor of the chamber (Hall and Wayman 1990).

This suggests that private donations to campaigns have different effects at the committee/agenda development stage and floor voting stage of the legislative process. Specifically, it suggests that donations bias legislative voting in committee, but have no effect on the extremity of voting behavior on the floor. If a donor is only providing donations to legislators already on the donor's side in order to encourage a different set of bills to emerge from committee, then the donation itself has no causal relationship with the positions of legislators receiving the money at the floor stage, but does have a strong causal relationship with the positions of legislators prior to floor voting. By extension, eliminating those donations through public financing of campaigns also should have no causal relationship with the positions of legislators who were receiving donations previously at the floor stage, but should moderate those legislators in committee. This implies that even though donors are more ideologically extreme than the general voting population, they only influence legislative behavior at the pre-floor stages of the legislative process and have little influence over extremity and polarization during roll calls.

Strategic Donor Hypothesis: (a) Committee Voting: Public financing of legislative elections reduces the ideological extremity of individual legislators' voting behavior in committees.

(b) Floor Voting: Public financing of legislative elections exerts no effect on the ideological extremity of individual legislators' roll call behavior on the floor of the chamber. 


\subsection{The No Strings Attached Hypothesis}

Our final perspective builds on work by Ansolabehere, de Figueiredo, and Snyder (2003), who observe that the vast majority of private campaign donations come from small, one-time contributions. This is at odds with investment models of donations, which suggest that donors are providing large sums of money in order to receive policy returns. Small donations are unlikely to be of enough value to extract any such benefits. Accordingly, in the face of many small donations, no single donor is sufficiently important to bias legislative behavior. Instead, Ansolabehere, de Figueiredo, and Snyder (2003) suggest that most campaign donations are not investments in legislative outcomes, but are forms of electoral participation with no expectations or policy "strings" attached. From this perspective most donors provide money to campaigns for a variety of nonpolicy based reasons, like the intrinsic rewards of having participated in the electoral process.

Because there are no strings attached to most campaign donations, and no single donor is powerful enough to impact legislative behavior, this perspective posits that neither committee nor floor voting is influenced by campaign donations. Even if donations tend to come from a more extreme set of citizens, those citizens donate to campaigns with no claim to control over future legislative behavior. This again implies that there is no causal relationship between donations and floor voting, but also implies that there is no causal relationship between donations and committee voting. Thus, moving to a public financing system should also have no influence on legislative behavior at either stage of the legislative process.

No Strings Attached Hypothesis: (a) Committee Voting: Public financing of legislative elections exerts no effect on the ideological extremity of individual legislators' voting behavior in committees.

(b) Floor Voting: Public financing of legislative elections exerts no effect on the ideological extremity of individual legislators' roll call behavior on the floor of the chamber.

These are inherently individual-level hypotheses, but the processes we outline have legislaturelevel implications when aggregated over many representatives. Accordingly, we test our expecta- 
tions with both individual- and legislature-level analyses from the American states.

\section{Public Financing in American State Legislatures}

Several states have instituted public financing programs for all or some of their state-level elections dating back to Minnesota in 1974. Here we utilize data from New Jersey, which implemented a pilot program for some assemblymembers in 2005 and 2007, and Arizona and Maine, which fully implemented legislative public financing in 2000. Both data sources have unique advantages for our analyses. The New Jersey program allows for an individual-level assessment of the effect of public financing — and thus a test of our full suite of hypotheses-because legislators in only some of the districts were given the option to use it. The second data set covers legislature-level polarization in Arizona and Maine. While those data do not allow us to separate polarization in committee and floor behavior, they do facilitate an examination of the aggregate consequences of public financing programs. We briefly discuss the details of the three states' programs below.

\subsection{New Jersey}

In 2004 the New Jersey state legislature approved the New Jersey Fair and Clean Elections Pilot Project (see Brickner 2008). The pilot program applied to Assembly campaigns in two of New Jersey's forty state legislative districts during the 2005 legislative elections. ${ }^{8}$ New Jersey's legislative districts are represented by two assemblymembers and one senator, making the legislative districts multimember assembly districts and ensuring that four legislators serving in 2006 and 2007 were given the option to use public financing. District selection for participation in the project was made by the major party state chairs, with each party chair choosing one district for participation. ${ }^{9}$ The districts chosen, in part, because they had a history of being moderately competitive and had large proportions of registered voters (Brickner 2008, 74). Importantly, factors related to our outcome of interest (legislators' voting behavior) were not cited as reasons for the

\footnotetext{
${ }^{8}$ New Jersey legislative elections are held in odd years with members elected in 2005 serving two-year terms from 2006-2007.

${ }^{9}$ Democratic chair Bonnie Watson Coleman selected the $6^{\text {th }}$ legislative district. The state Republican chair, Tom Wilson, selected the $13^{\text {th }}$ legislative district.
} 
selections. ${ }^{10}$

Following the 2005 pilot, the New Jersey Citizens' Clean Elections Commission made several recommendations, including an expansion of the project to incorporate more legislative districts in 2007. In December of 2006, the New Jersey Assembly voted to continue the pilot project in 2007 by a 67-to-11 margin (with two abstentions). The 2007 version of the pilot project extended the program to three legislative districts and did not require any of the districts that participated in 2005 to participate again in 2007. Additionally, the district selection in 2007 was made by state legislative leaders and was to include two districts with unified representation in the Assembly and one district with a split delegation. ${ }^{11}$

The Clean Elections Pilot Project was unexpectedly not renewed for the 2009 state legislative elections. $^{12}$ Assembly Speaker Joseph Roberts cited a ruling by a federal appeals court against provisions of Arizona's publicly-financed legislative elections as the motivation for ceasing the pilot program. Ultimately, while several bills extending the project were considered during the 2008 legislative session, each failed to advance out of committee consideration, and New Jersey's experiment with publicly financed legislative elections came to an end.

However, for our purposes, this short-term implementation of public financing by the New Jersey legislature provides us with a valuable natural experiment. By administering the treatmentthe option to take public funds for one's campaign - to candidates in only a subset of the state's legislative districts, New Jersey's Clean Elections Pilot Project yields an excellent opportunity for comparing legislative behavior before and after the implementation of public financing. Of course, the assignment of public financing to the legislative districts was not random. Nonetheless, the

\footnotetext{
${ }^{10}$ Specifically, the initial act authorizing the pilot program in 2005 nominated two slates of three districts—one slate each for Democratic- and Republican-leaning districts. All of the districts nominated were deemed competitive, where competitive meant election results were typically within the reach of the opposition party. One district was chosen from each slate by each state party's committee chairperson. In 2007, legislative leaders choose one district from each party's "controlled" districts, while an ad hoc committee of five members (three members of the Clean Elections task force, a former governor, and a former state Democratic chairperson) selected the split district for the program.

${ }^{11}$ Democratic legislative leaders selected the $37^{\text {th }}$ legislative district, Republican leaders choose the $24^{\text {th }}$ legislative district, and a bipartisan committee of legislative leaders selected the $14^{\text {th }}$ legislative district as the split delegation participant in the project.

${ }^{12}$ Both the 2005 and 2007 versions of the pilot project received favorable evaluations and were strongly recommended to both continue and be expanded (Brickner 2008). Consequently, there is little reason to believe participating legislators would have expected to return to private financing in the future.
} 
legislators who took public financing did not directly affect which districts were chosen, and thus self-selection only occurred after public financing was allowed in their districts. Overall, this sort of a pilot project in institutional change is as close to a fully realized natural experiment with public financing as legislative scholars are likely to encounter.

\subsection{Arizona and Maine}

The public financing programs implemented in Arizona and Maine were larger in scale than the pilot program in New Jersey. Arizona and Maine approved their programs for state legislative races in 1998 and 1996, respectively, with each going into effect in 2000. While each program has its own unique history, they also share several commonalities. For instance, both were born out of past instances of corruption in state government and both came into law through direct democracy. The acts instituting the two programs even resemble one another in many characteristics (Malhotra 2008).

Voters passed the Maine Clean Elections Act as a ballot initiative by a 12 percentage-point margin in 1996. Brickner $(2008,53)$ cites several political factors from the 1980s and 1990s that ultimately led to the decision: "a proliferation of wealthy and self-financed candidates, a divisive government shutdown, and a ballot-stuffing scandal involving Maine's Speaker of the House of Representatives." The state legislature failed to pass dozens of bills aimed at reforming campaign finance, which ultimately led advocates to use the citizen initiative. Even then, the legislature attempted to draft its own public finance measure so that it could exert more control over the process, though this effort eventually failed. Organization by several public interest groupsCommon Cause, the League of Women Voters, AARP, and AFL-CIO_made the difference in the success of public finance (Brickner 2008, 54). The public officials affected by it were undoubtedly reluctant participants when candidates were given the option in 2000 . However, $31 \%$ of candidates in Maine participated in the program (Malhotra 2008).

Corruption in government also galvanized voters in Arizona to enact public financing after Governor Fife Symington's resignation over extortion and bank fraud charges (Brickner 2008, 56). A similar list of public interest groups that operated in Maine formed a coalition and worked 
through the citizen initiative to put the Citizens' Clean Election Act on the ballot in 1998. Opposition formed from several other groups, such as the Arizona Trial Lawyers Association and some state legislators, but it ultimately passed with a two percentage-point margin. It went into effect in 2000 and approximately 25\% of candidates participated (Malhotra 2008). The program remained unchanged until being amended in 2007 and struck down by the U.S. Supreme Court in 2011. ${ }^{13}$

Two main features of the history of public financing in Arizona and Maine make them useful testing grounds for our theoretical expectations. First, while it is not the case that public financing was assigned randomly to these states, the legislators themselves were certainly not leading the charge. This mitigates the issue of self-selection into treatment to some degree. Additionally, our main outcome of interest-legislative polarization — was not a central reason for the implementation of public financing. Rather, proponents were concerned with curbing corruption in state government and leveling the playing field for political candidates. As a result, we are not concerned that legislators might have falsely and intentionally altered their roll call behavior to create the illusion of an effect of public financing.

\section{Estimating the Causal Effect of Public Financing}

Our objective in testing the theoretical framework described above is to estimate the causal effect of the advent of public financing on the extremity of legislative voting. To identify this causal effect, we employ the potential outcomes perspective on causal inference (for a review, see Morgan and Winship 2007). In this case, we define the option to take public financing as the treatment applied to legislators or legislatures. There exists for each legislator or legislature in the population of interest a random variable $Y$ which defines its potential outcome under the treatment of public financing $\left(Y^{1}\right)$ and control, or no public financing $\left(Y^{0}\right)$. Then, for case $i$ (whether a legislator or legislature), the individual-level causal effect, $\delta_{i}$, is defined as the difference between

\footnotetext{
${ }^{13}$ As described below, our analysis ends in 2007 to avoid the possibility of a contaminating effect from the legal status of the Arizona program.
} 
that observation's realizations of $Y$, denoted $y_{i}$ as follows:

$$
\delta_{i}=y_{i}^{1}-y_{i}^{0}
$$

Another relevant population-level random variable is the treatment indicator, $D$. Individual realizations from this variable, denoted $d_{i}$, are equal to 1 if a case is exposed to public financing and 0 otherwise. This leads to the fundamental problem of causal inference: while each case has a potential outcome in each causal state (treatment and control), we only observe one of those two potential outcomes (Holland 1986). For instance, we can observe a legislator's level of roll call extremity at a given point in time under public financing (e.g., $y_{i}^{1}$ ), but we do not observe that legislator's counterfactual level of extremity: his or her potential outcome at that same time point under no public financing $\left(y_{i}^{0}\right)$. Accordingly, we must focus our attention on generating a counterfactual case through other means. This typically involves using temporal variation and/or untreated units as counterfactuals for the treated observations.

An additional roadblock to identifying a causal effect is the fact that public financing was not randomly assigned to states or to individual legislators in states (see above). Random assignment would (in expectation) ensure that no systematic differences exist between the treatment and control groups. This would render the observations in control satisfactory counterfactuals for the treated observations. In reality, states and legislators decide for themselves whether to implement and participate in public financing programs. Although we make the case above that these decisions were unrelated to our outcome of interest in the states we examine, there still might be differences between the two groups that could also affect polarization. Consequently, we must take extra steps to construct proper counterfactuals. We achieve this with three different methods: synthetic case control (which we present here), matching (in the appendix), and difference-in-differences (also in the appendix). ${ }^{14}$ In each case we focus on the effect of public financing on legislators and/or legislatures who tend to choose to use it, or the treatment effect on the treated (see Morgan and

\footnotetext{
${ }^{14}$ The replication materials include data and code for performing all three of these analyses.
} 
Winship 2007, 42). ${ }^{15}$

\subsection{Synthetic Case Control}

Synthetic case control is one of several options for estimating causal effects. It is particularly useful for examining the effects of institutions, economic shocks, or other interventions on large, aggregated units, such as countries, regions, or states (e.g., Abadie and Gardeazabal 2003; Abadie, Diamond, and Hainmueller 2010, 2011, 2014; Keele, Malhotra, and McCubbins 2013). The objective is to create an untreated "synthetic" version of a treated case through a weighted combination of the control cases in a "donor pool." It is unlikely that any single untreated legislator or state is a useful comparison for a treated case, but a combination of several control cases may provide such a counterfactual. This method is also particularly useful in our context because we have small samples of data (Abadie, Diamond, and Hainmueller 2014). However, we also show in the appendix that matching and a regression-based approach using difference-in-differences (DID) produce substantively identical results.

We briefly outline synthetic case control here; see Abadie, Diamond, and Hainmueller (2010) and Abadie, Diamond, and Hainmueller (2011) for complete details. The key input is data on an outcome of interest (e.g., extremity in voting) as well as relevant pre-treatment covariates, measured over time such that there exists data before and after the intervention (public financing). To construct a synthetic case for a given treated observation, the method defines a $J \times 1$ vector of weights, $\mathbf{W}$, where $J$ is the number of available control observations. The weights in $\mathbf{W}$ are constrained to be non-negative and sum to 1 , and any change to them produces a different candidate synthetic control unit. The goal of the method is to choose values for $\mathbf{W}$ that produce a synthetic control unit that most closely resembles the treated unit on the pre-treatment characteristics. More specifically, the algorithm utilizes a numerical optimization routine to choose a set of weights, $\mathbf{W}^{*}$, that minimize an objective function defining the distance between the treated and synthetic control units.

\footnotetext{
${ }^{15}$ The treatment effect on the treated is likely the most useful quantity of interest in this case. Public financing programs have never been mandatory, and so it makes sense to assess their effects on those who choose to use them.
} 
The next step is to use the weights representing the optimal synthetic control unit, $\mathbf{W}^{*}$, to create a counterfactual outcome. Define a $T \times 1$ vector $\mathbf{y}_{\mathbf{i}}$ as the observed outcome variable (voting extremity) for the treated unit $i$ at the $T$ time periods and $\mathbf{y}_{\mathbf{0}}$ as a $T \times J$ matrix of the outcome variable for the control units over the same periods. The method computes a predicted level of extremity for the synthetic unit, $\mathbf{y}_{\mathbf{i}}^{*}$, equal to $\mathbf{y}_{\mathbf{0}} \mathbf{W}^{*}$. This predicted outcome, $\mathbf{y}_{\mathbf{i}}^{*}$, can then be compared to the actual outcome, $\mathbf{y}_{\mathbf{i}}$. Notice that because the synthetic control unit is constructed to be a unique counterfactual for a given treated unit, differences between the prediction and the actual outcome after the intervention can be used as an approximation of $\delta$, the individual-level causal effect defined in Equation 1. Of course, the synthetic unit is not a perfect counterfactual, but the difference can be used to provide evidence in favor of a causal effect in the treated unit (for more on this point, see Abadie, Diamond, and Hainmueller 2010, 495).

One crucial strength of the synthetic case control method is that examining its performance in generating a counterfactual unit is straightforward. Specifically, fit can be measured as the degree to which the counterfactual prediction matches the actual outcome before the intervention. A close match indicates that the synthetic unit in $\mathbf{W}^{*}$ does, in fact, represent a counterfactual that is (nearly) identical to the treated unit. As a result, its post-treatment prediction can be trusted as an accurate measure of the "what-if" scenario had the treated unit not been exposed to the treatment. This fit can be evaluated through graphical displays of the predicted and actual outcomes and formalized through mean squared prediction error during the pre-intervention period (MSPE, see Abadie, Diamond, and Hainmueller 2010, 2011).

\subsection{Causal Inference in Small Samples}

In the two analyses we describe below we employ a relatively small amount of data to evaluate our hypotheses. Indeed, our legislator-level analysis includes five publicly-financed legislators in New Jersey and our state-level analysis examines the effect of public financing in two states. Accordingly, we must acknowledge that our results should be interpreted with appropriate caution. However, we contend that this analysis is still useful for two reasons.

First, the implementation of public financing among a subset of legislators in New Jersey pro- 
vides a unique opportunity to isolate the impact of a significant electoral rule change, holding other institutional and contextual factors constant. New Jersey's experiment with public financing produces better causal leverage on a critical question than is typically available to researchers. Contrast the New Jersey program, where only a subset of legislators received the option of public financing (and accepted it), to analyses of legislators in states that adopt public financing for the entire legislature. In our view, legislators who never received the option constitute better counterfactuals than do legislators who received the option but did not accept it. In short, while the data we have are few, they are of high quality.

Furthermore, our state-level analysis leverages the classic strength of comparative state politicsthe use of the states as "laboratories of democracy" (Morehouse and Jewell 2004). The states are easily comparable because they developed out of similar political histories, but exhibit enough unique variation to provide researchers with analytic leverage. Thus, we contend that examining the legislator- and legislature-level effects of state public financing programs is a worthwhile scholarly endeavor, even if those programs have not yet provided a large amount of data.

Additionally, the synthetic case control method is ideal for small sample inference; Abadie, Diamond, and Hainmueller (2014) point out that it "opens the door to precise quantitative inference in small-sample comparative studies" (1). Rather than estimating a single parameter for the causal effect of public financing, the method allows us to turn our small sample into several "quantitative case studies." By creating unique counterfactuals for each legislator and state, we address the specific question of what would have happened if that particular individual or state had decided not to take or adopt public financing. Thus, while we do not have the same statistical power that a large sample would afford, we can maximize internal validity from the cases that are available. Additionally, in the appendix we bolster our synthetic case analyses with similar results from matching and a difference-in-difference approach. While it remains true that we are leveraging a small set of treated units to draw inferences, we see consistent results across a variety of methods.

This quantitative case study approach holds particular appeal for the study of institutional reforms. Such reforms are typically rolled out in piece-meal fashions. For example, legislative term 
limits were implemented slowly across small sets of states over a period of several years (Carey, Niemi, and Powell 2000), convenience voting laws have similarly been rolled out at very different rates in very different places (Gronke, Galanes-Rosenbaum, Miller, and Toffey 2008), and the first state politics application of the synthetic case approach was the examination of a policy change in a single state (Abadie, Diamond, and Hainmueller 2010). The likelihood that major institutional reforms will be implemented across wide swaths of legislative settings such that more traditional large- $\mathrm{N}$ analyses would be appropriate, while still providing scholars with the necessary ability to compare those experiencing the reform to those who have not, is low. Thus, scholars seeking to speak to the effects of subnational institutional reforms on elite behavior will usually be in the position of dealing with a limited number of treated cases, a circumstance that makes a quantitative case study a useful tool.

\subsection{Legislator-Level Analysis}

To test our hypotheses at the legislator level, we utilize roll call data from the New Jersey Assembly during the period from 2002-2010. We generate our outcome variable of interest, the extremity of legislators' roll call voting, by applying Martin and Quinn's (2002) dynamic ideal point estimator to 1,058 committee votes and 1,438 floor votes. See the appendix for a complete description of this process. We use non-unanimous votes for all legislators who served for the entire time period of 2002-2010 and generate separate ideal point estimates for votes in committee and votes on the floor. ${ }^{16}$ This produces sets of ideal points for each legislator that are comparable across time. Then, to generate our measure of extremity, we compute the absolute value of the difference between each legislator's estimated ideal point and the chamber mean for that session (committee votes) or year (floor votes). ${ }^{17}$

Next, we collected the following covariates to construct the synthetic cases from the donor

\footnotetext{
${ }^{16}$ This yields 22 potential control legislators for the committee vote ideal points and 28 potential control legislators for the floor vote ideal points. The floor vote ideal points are generated for each year. The committee vote ideal points are generated over two-year sessions because the New Jersey Assembly's records do not separate committee votes by year.

${ }^{17}$ One potential problem is that changes in chamber composition could affect the chamber mean, and thus artificially change a legislator's extremism. That does not appear to be a severe issue in our data, as the chamber mean only varies by $8 \%$ of the variable's scale across all the year we observe.
} 
pool (legislators who were not given the public financing option): ideal point standard deviation, an indicator for legislative leaders, the amount of money raised in the last campaign, seniority in years, vote percentage in the most recent election, race, gender, party, and district Democratic presidential vote share in 2000. Recall from above that the logic of the synthetic case control method stipulates that while one legislator may not serve as a useful counterfactual for another, a weighted combination of legislators with respect to these relevant variables may provide such a counterfactual. ${ }^{18}$ Furthermore, we can empirically assess the performance of these variables in constructing the counterfactual. Finally, because it may be possible that public financing exerts influence on only some votes cast by legislators (see Witko 2006), we report results in the appendix from analyses of different subsets of these data. These additional results are consistent with what we report below.

\subsubsection{Graphing the Actual and Synthetic Legislators}

Figures 1 and 2 graph the extremity of each legislator's committee and floor vote ideal points (solid lines) and the synthetic case predictions (dashed line) before and after taking public financing. ${ }^{19}$ Figure 1 plots legislators who participated in the public financing program in 2005 and Figure 2 plots those who took public financing in 2007. The rug plots on the y-axes of each graph denote the distribution of the dependent variable to give perspective on the magnitude of the change (or lack thereof) for each legislator.

\section{[Insert Figure 1 here]}

\section{[Insert Figure 2 here]}

The first point to note from these figures is that our covariates listed above yield high-quality synthetic cases to use as counterfactual comparisons. This is shown by small values for the MSPE_-which measures error between the synthetic and treated cases before treatment—relative to the range of the dependent variable. ${ }^{20}$ Additionally, it is reinforced by the observation that,

\footnotetext{
${ }^{18}$ See the appendix for a listing of the optimal weights used for each treated legislator.

${ }^{19}$ Alison L. McHose was not in the legislature in 2002 and thus is omitted from the committee vote analysis.

${ }^{20}$ Specifically, the committee vote and floor vote extremity measures range from 0.53 to 4.27 and 0.008 to 2.82 , respectively. The pre-treatment MSPE for committee vote extremity ranges from 0.0001 to 0.02 with a median of
} 
in general, the synthetic predictions and actual outcomes before the start of public financing are visually similar. Indeed, in most cases the two lines are nearly overlaid on top of one another. With respect to ideal point extremity, we generated synthetic legislators that look a lot like real legislators. Even in the worst-fitting case_Linda R. Greenstein's floor vote ideal points (Figure 2, panel c) - the synthetic case generally follows the same pattern as the actual outcome, but is simply shifted up slightly on the y-axis. Overall, the quality of our synthetic cases gives us confidence that we have informative counterfactuals to use for causal inference.

The next step is examining the post-intervention outcomes. Recall that we posited four possible theoretical processes regarding the effect of public financing on ideal points: a decrease in extremity (moderating hypothesis), an increase in extremity (flanking hypothesis), an increase in committee vote extremity but no change in floor vote extremity (strategic donor hypothesis), and no change in committee or floor vote extremity (no strings attached hypothesis). Evidence of a decrease in ideal point extremity would come from an actual level (solid line) lower than the predicted level had the legislator not received public financing (dashed line). The opposite pattern-actual values larger than predicted values-would provide evidence of increased extremity due to public financing. Finally, minimal differences between the two lines after the advent of public financing would suggest that public financing exerts little or no effect on the extremity of ideal points.

The results in Figures 1 and 2 show that across committee and floor vote ideal points, the differences between legislators' predicted extremity had they not received public financing and actual extremity after receiving public financing are small. ${ }^{21}$ For those legislators that do exhibit some differences, the direction of those differences is not consistent. For example, Louis D. Greenwald's floor vote ideal point became slightly more extreme than expected in the year after taking public money, but his voting behavior in subsequent years became less extreme (Figure 1, panel a). Furthermore, Greenwald's committee vote ideal point trended in the less extreme direction after taking public financing.

0.0006 . For floor votes the range is 0.0005 to 0.13 with a median of 0.001 .

${ }^{21}$ This pattern is evident by looking at all of the time periods after public financing or only looking at the first period after public financing. 
Most importantly, the general trend among the treated legislators' level of extremity is a remarkable similarity with the synthetic predictions. Consider Samuel D. Thompson's ideal points (Figure 1, panels $\mathrm{c}$ and d), which show almost no change compared to the what-if scenario had he not taken public financing in 2005. The same pattern holds for the legislators who took public financing in 2007 (Figure 2). Alison L. McHose, Linda R. Greenstein, and Gordon M. Johnson show only very small differences between actual and predicted ideal point extremity. Comparing those differences to the distribution of ideal point extremity in the whole sample of data (see the rug plots on the y-axes) shows that they are not substantively significant. In short, Figures 1 and 2 provide evidence in favor of the no strings attached hypothesis-public financing exerts negligible effects on the extremity of legislators' ideal points in committee or on the floor.

\subsubsection{Inference}

Figures 1 and 2 demonstrate that the individual-level effect of public financing is essentially zero, but do not allow for any formal inferential statements. The synthetic case control method allows for statistical inference via placebo tests. To construct the placebo tests we apply the algorithm to the control legislators in the donor pool. Because they did not participate in the program, we know that in expectation the "effect" of public financing is zero for those legislators. Thus, any observed change in the extremity of their ideal points after the implementation of the program is due to random chance. We can then compare the results for the placebo legislators with those who took public financing.

Figure 3 presents "gaps" analyses using the committee vote (panel a) and floor vote (panel b) ideal points. Instead of plotting one line for the actual outcome and another for the synthetic prediction, each line represents the difference between actual and predicted outcomes for each legislator. The gray lines represent each of the placebo legislators and the black lines represent each of the treated legislators. ${ }^{22}$ All of the lines are near zero before the advent of public financing, indicating good synthetic case fit. ${ }^{23}$ The placebo legislators' gaps between actual and predicted

\footnotetext{
${ }^{22}$ There are 21 placebo legislators in the committee vote results (panel a) and 24 placebo legislators in the floor vote results. Following Abadie, Diamond, and Hainmueller (2010), we discard any control legislators whose MSPE is five times that of the worst-fitting treated case's MSPE.

${ }^{23}$ We use 2005 as the intervention point because that is when public financing was first available to some districts.
} 
should vary randomly after public financing. Then the treated legislators' gaps can be compared to the placebo gaps to assess the rarity of the treated legislators' gaps.

\section{[Insert Figure 3 here]}

Both panels of Figure 3 show that, generally, the gaps between actual outcomes and synthetic predictions for the treated legislators (black lines) are not any more or less rare than what we would expect due to random chance (gray lines). The gaps for Louis D. Greenwald do appear at the edges of the "clouds" of gray lines in each graph, which is consistent with the evidence in Figure 1 that his ideal point extremity decreased to some degree after public financing. But the lines for Greenwald are not clearly separated from the group of placebo legislators. Furthermore, even if we consider the lines for Greenwald sufficiently rare to be considered evidence in favor of an effect of public financing, the other four treated legislators' gap lines fall squarely in the center of the cloud of placebo lines. This provides evidence of little or no effect.

Additionally, following Abadie, Diamond, and Hainmueller (2010, 503), we computed the ratio of post-intervention MSPE to pre-intervention MSPE for each treated and placebo legislator. The distribution of these ratios allows for the computation of permutation-based $p$-values to test the null hypothesis that a given treated legislator's gap is statistically significantly different from zero. None of these $p$-values allowed for the rejection of this null, even at the generous level of $p<0.10$ (one-tailed). This provides additional evidence that the treatment effects we find are no different from what we would expect due to random chance.

In sum, Figures 1-3 indicate considerable support for the no strings attached hypothesis. We find that legislators' ideal point extremity in committee or on the floor is not affected by whether their campaigns are financed by public money. ${ }^{24}$ Importantly, this is a precisely-estimated negligible effect, not simply a lack of a finding due to poor fit between model and data (Rainey 2014). Indeed, the close similarity between actual and predicted outcomes in the time periods before public financing indicate that our synthetic versions of each treated legislator-which were constructed from the covariate values of several control legislators-closely resemble the real thing.

\footnotetext{
${ }^{24} \mathrm{We}$ also come to this same conclusion using matching and difference-in-differences. See the appendix for details.
} 
With high-quality counterfactuals, we can be confident that the synthetic outcomes after public financing are accurate predictions for what would have happened had the treated legislators not taken public financing. With that in mind, we show very clearly that when it comes to ideal point extremity, not much would have changed.

Of course, these results come from five individual legislators in one chamber of one state's legislature. This leads to two additional questions: does the same pattern that appears at the individual level also hold at the aggregate level? Also, can we generalize this finding beyond just one state? We turn to those questions next in a state-level analysis of the effect of public financing on legislative party polarization.

\subsection{State-Level Analysis}

To test our hypotheses at the state level, we utilize aggregate data on state legislative ideal points from Shor and McCarty (2011). ${ }^{25}$ Specifically, our outcome of interest in this analysis is the ideological distance between the party medians, averaged across chambers, from 1993 to 2007. Shor and McCarty (2011) use this as a measure of ideological polarization between the parties in the legislature. The time period that their data cover fits well with the implementation of public financing as an option for candidates in Arizona and Maine in 2000. ${ }^{26}$ Analyzing the effect of public financing on party polarization provides an aggregate-level complement to our individual analysis from New Jersey. As before, we employ synthetic case control to test our hypotheses. In this case we generate synthetic versions of Arizona and Maine from the pool of states that did not implement state legislative public financing programs during this period. ${ }^{27}$

\footnotetext{
${ }^{25}$ It is important to note that Shor and McCarty's (2011) data provide a single ideal point for each legislator over the course of their entire careers, meaning legislators do not have ideal points that change over time. Thus, our tests in this section cannot uncover individual legislator-level adaptation to public financing. However, our state-level analyses do allow for examination of whether public financing influences legislative polarization through the composition of the legislature. The only way for chambers to become more polarized using Shor and McCarty's (2011) data is for moderate legislators to be replaced by extreme legislators. In this way, our New Jersey analysis can be thought of as testing for individual adaptation to public financing, while our state-level analysis considers the replacement effects of public financing.

${ }^{26}$ Public financing programs do not require participation, and thus it could be argued that the treatment was weak in these cases. Indeed, only about $25-31 \%$ of the eligible candidates for each legislature actually took public money (Malhotra 2008). However, because the voluntary nature of these programs is rooted in the First Amendment, our results are informative because they reflect what can reasonably be expected from other programs in the future.

${ }^{27}$ We omit Minnesota from the donor pool because that state implemented a public financing program in 1974 that includes state legislative races (Brickner 2008). Connecticut and New Jersey have implemented similar programs in
} 
We use the following covariates in the construction of the synthetic cases from states without public financing (data sources in parentheses): the average distance between any two legislators (a "party-free" measure of polarization, see Shor and McCarty 2011), state citizen ideology, state citizen ideological extremity, and state government ideology (Berry, Ringquist, Fording, and Hanson 1998), legislative professionalism (Squire 2007), U.S. Census data on state income, unemployment, population, population density, amount of federal grants, and gross state product (Keele, Malhotra, and McCubbins 2013), and indicators for divided government, Democratic party control, closed-primary states, regions, and term limits. ${ }^{28}$

\subsubsection{Graphing the Actual and Synthetic States}

Figure 4 graphs the actual difference in party medians (solid lines) and the synthetic case predictions (dashed line) before and after the implementation of public financing in Arizona (panel a) and Maine (panel b). As in the New Jersey analysis above, we include rug plots of the dependent variable to give perspective on the magnitude of the change (or lack thereof) for each state.

\section{[Insert Figure 4 here]}

As before, our first step is to assess the quality of the synthetic cases. Figure 4 shows that our list of covariates produced synthetic states that closely match the actual states with respect to party polarization before public financing went into effect in 2000. In each state the MSPE values reflect a very small amount of error relative to the range of the dependent variable between the synthetic and treated states before treatment. ${ }^{29}$ Furthermore, visual inspection of the graphs reveals two lines in each one that are nearly overlaid on top of each other. In short, we have strong evidence that our synthetic versions of Arizona and Maine look a lot like the real states. This

recent years, but those states' programs were not active during the 1993-2000 period and thus they can be used as valid control states in our analysis. Finally, due to missingness in the some of the covariate data described below we omit Alaska, Hawaii, and Nebraska, producing a donor pool of 44 potential control states.

${ }^{28}$ The term limits variable deserves special mention, as both Arizona and Maine limit the terms of their state legislators. The implementation of term limits does not constitute a confounding effect in our analysis for two reasons. First, in Maine term limits were enacted in 1996, four years prior to public financing. In Arizona the first legislators were termed out in the same year as public financing (2000). However, we allow the algorithm to account for term limits in constructing the synthetic cases; if term limits matter for legislative polarization, our methodology accounts for that in creating the synthetic states.

${ }^{29}$ The dependent variable ranges from 0.41 to 3.00. The MSPE values are 0.001 (Arizona) and 0.003 (Maine). 
means we can be confident that the synthetic cases' predictions of polarization levels from 20012007 accurately reflect what would have happened if Arizona and Maine had not adopted public financing programs.

In examining the post-intervention levels of polarization, recall that our theoretical expectations include four possible processes: the moderating hypothesis, the flanking hypothesis, the strategic donor hypothesis, and the no strings attached hypothesis. However, because the Shor and McCarty (2011) data do not include separate measures for committee and floor polarization, we are constrained in our ability to produce a critical test of all four hypotheses. Without a measure of state-level committee polarization, we cannot separate the strategic donor and no strings attached hypotheses because they make identical predictions for floor vote polarization. However, we can still assess whether public financing produces a moderating, polarizing, or negligible effect on the ideological distance between the parties.

The results in Figure 4 are generally consistent with our individual-level findings from New Jersey: public financing appears to have little or no effect on legislative polarization. In Arizona (panel a), the actual difference in party medians drops slightly lower than its synthetic prediction in 2001 and 2002. Then in 2003 both the actual level of polarization and the synthetic prediction increase. The increase is somewhat larger for the actual data, and so by 2007 the difference between the two lines is more noticeable. This could suggest a polarizing effect. However, even the difference in 2007 is still relatively small: about 0.33 on a variable that ranges from 0.41 to 3.00 and has a standard deviation of 0.41. Consequently, in our view it does not seem to be the case that public financing produced a clear increases in polarization in the Arizona legislature.

In Maine (panel b), the actual and predicted levels of polarization remain quite similar for the entire post-2000 time period. The actual level of polarization moves a bit higher in 2003, but the differences are substantively small when compared to the distribution of polarization (see the rug plot on the y-axis). Furthermore, the predicted level of polarization also rises in 2003. In short, there is no evidence in Figure 4 suggesting that public financing had a moderating or polarizing effect on the state legislatures of Arizona and Maine. 


\subsubsection{Inference}

Figure 5 presents the gaps analysis for each state (black lines) against 40 placebo states (gray lines). ${ }^{30}$ Instead of plotting one line for the actual outcome and another for the synthetic prediction, each line represents the difference between actual and predicted outcomes for each state. As before, the placebo states' gaps between actual and predicted should vary randomly after public financing. Then the treated states' gaps can be compared to the placebo gaps to assess the rarity of the treated states' gaps.

\section{[Insert Figure 5 here]}

Similar to the legislator-level evidence from New Jersey, Figure 5 shows that the gaps between actual outcomes and synthetic predictions for the treated states are not any more or less rare than what we would expect due to random chance (gray lines). In each case the gap line is clearly within the cloud of gray lines for all of the post-2000 period, indicating that the slight increases in polarization compared to the synthetic predictions are nowhere near large enough to constitute evidence of a polarizing effect. We also computed permutation-based $p$-values for these gaps from the ratio of post-intervention to pre-intervention MSPEs. With $p$-values of 0.41 (Arizona) and 0.24 (Maine), the null hypothesis of no effect cannot be rejected.

\subsection{Summarizing the Findings}

Before concluding, we briefly summarize our synthetic case control results. Table 1 reports the average gap between the actual outcomes and the synthetic predictions after treatment for the New Jersey assemblymembers who took public financing and the Arizona and Maine legislatures. The table also reports the mean effect within those two groups.

[Insert Table 1 here]

Overall, we find evidence that the effect of public financing on legislative extremity is negligible. We arrive at our conclusion for three different reasons. First, the estimated effects of public

\footnotetext{
${ }^{30}$ Again, we discarded control states whose MSPE was five times that of our worst-fitting treated state's MSPE (Maine).
} 
financing across our analyses are consistently small in magnitude (see Table 1). Indeed, while the dependent variables range from 0.53 to 4.27 (New Jersey committee vote ideal points), 0.008 to 2.82 (New Jersey floor vote ideal points), and 0.41 to 3.00 (Arizona and Maine difference in party medians), the average post-intervention difference between the actual and synthetic cases is never greater in magnitude than 0.23. Second, the placebo tests depicted in Figures 3 and 5 (and their corresponding $p$-values) indicate that the effects we estimate are consistent with effects generated due to random chance. Finally, in our difference-in-differences analysis in the appendix, we follow Rainey's (2014) framework for arguing for negligible effects and reach the same conclusion.

\section{Conclusions}

The potentially strong influence of private donations to election campaigns has led to a number of efforts at campaign finance reform. One of the most radical approaches to reform has been the institution of publicly-financed elections, in which candidates can opt to eschew private donations and take taxpayer money to run their campaigns. Proponents of such reforms suggest that publiclyfinanced campaigns increase electoral competition, deter corruption in government, and reduce extremist voting behavior. Opponents counter that such programs dilute the political voice of potential donors, violating their First Amendment rights to free expression. The U.S. Supreme Court has, by and large, agreed with this latter view. Most importantly for our purposes, both proponents and opponents of publicly-financed campaigns - as well as some academic and media observers-assume that donations play an important role in legislative behavior and polarization between legislative parties. Indeed, the debate about public financing's constitutionality does not focus on whether it has an effect, but rather on whether its role in shaping legislative behavior is appropriate.

Contrary to this assumption, we provide evidence that public financing exerts a negligible effect on legislative voting behavior. Using the New Jersey Assembly's public financing pilot project and a synthetic case study approach, our empirical evidence suggests that legislators vote virtually the same way when they are publicly- or privately-financed, both in committees and on the floor. We then show additional evidence of this negligible effect with state-level analyses of the public 
financing programs in Arizona and Maine. While campaign donations may be an important form of political speech for donors, that speech has little influence on the extremity of individual legislators or polarization of legislative parties. Of course, as discussed above we have a relatively small sample of data from which to draw our conclusions. Nonetheless, our evidence does support existing research that suggests donations are a form of participation with no real expectations attached to them. Because donors do not expect returns on their electoral investments, and legislators fail to provide any real returns on those investments, eliminating those investments produces no real change in the extremity of legislative voting.

While our research provides support for the notion that public financing has no effect on voting behavior, publicly-financed elections may have a host of other important effects worth further investigation. For example, public financing might influence other aspects of legislators' behavior, such as bill authoring, sponsorship, or co-sponsorship. Removing private donations may also increase the trust citizens have in their legislators, thus encouraging participation. Public financing may encourage challenges to incumbents by preventing the accumulation of electoral war chests. Alternatively, because most campaign donations are small gifts from one-time donors, eliminating such donations may disproportionally advantage organizations with sufficient funding to hire legislative lobbyists. Without the offsetting influence of campaign donations by the general public, publicly-financed elections may actually make interest groups and businesses more powerful influences on government outcomes. Thus, continued research on the potential beneficial and deleterious effects of publicly-financed legislative elections is strongly warranted.

The Supreme Court's decision to hear several cases in recent years on public financing of elections reflects the critical importance of monitoring how money influences political outcomes. Indeed, the choice between allowing people to freely use their resources to state their values and limiting the negative consequences of economic inequality means that the use of taxpayer money for campaign finance will always produce a complex discussion. However, in advancing this dialogue we contend that relevant parties should be careful with assumptions about how public financing actually impacts politics. It might seem likely that legislators only respond to their ideologically 
extreme donor bases, and thus removing those donors' influence can give political voice to people who do not have the means to donate. But when put to an empirical test, that supposition receives no support. While public financing may have many normative benefits, such as facilitating electoral competition and/or reducing corruption, we cannot claim from the evidence presented here that it brings legislators from opposing parties together in compromise. 


\section{References}

Abadie, Alberto, Alexis Diamond, and Jens Hainmueller. 2010. "Synthetic Control Methods for Comparative Case Studies: Estimating the Effect of California's Tobacco Control Program." Journal of the American Statistical Association 105(490): 493-505.

Abadie, Alberto, Alexis Diamond, and Jens Hainmueller. 2011. "Synth: An R Package for Synthetic Control Methods in Comparative Case Studies." Journal of Statistical Software 42(13): $1-17$.

Abadie, Alberto, Alexis Diamond, and Jens Hainmueller. 2014. "Comparative Politics and the Synthetic Control Method." Forthcoming, American Journal of Political Science.

Abadie, Alberto, and Javier Gardeazabal. 2003. "The Economic Costs of Conflict: A Case Study of the Basque Country." American Economic Review 93(1): 112-132.

Ansolabehere, Stephen, John M. de Figueiredo, and James M. Snyder. 2003. "Why is There so Little Money in U.S. Politics?” Journal of Economic Perspectives 17(1): 105-130.

Bafumi, Joseph, and Michael C. Herron. 2010. "Leapfrog Representation and Extremism: A Study of American Voters and Their Members in Congress." American Political Science Review 104(3): 519-542.

Bartels, Larry M. 2008. Unequal Democracy: The Political Economy of the New Gilded Age. Princeton, NJ: Princeton University Press.

Berry, William D., Evan Ringquist, Richard C. Fording, and Russell L. Hanson. 1998. "Measuring Citizen and Government Ideology in the American States, 1960-93." American Journal of Political Science 41(1): 327-348.

Blumenthal, Paul. 2013. "Barack Obama: Citizens United Contributes to Extreme Politics in Washington." Huffington Post. 8 October 2013. Retrieved January 9, 2015.

http://www.huffingtonpost.com/2013/10/08/barack-obama-citizens-united_n_4065786.html.

Box-Steffensmeier, Janet M. 1996. "A Dynamic Analysis of the Role of War Chests in Campaign Strategy.” American Journal of Political Science 40(2): 352-371.

Brickner, Benjamin T. 2008. "Clean Elections: Public Financing in Six States, including New Jersey's Pilot Projects.” Technical Report, Eagleton Institute of Politics.

Carey, John M., Richard G. Niemi, and Lynda W. Powell. 2000. Term Limits in the State Legislatures. Ann Arbor, MI: University of Michigan Press.

Common Cause. 2014. "The Benefits of Fair Elections.” Retrieved January 9, 2015.

http://www.commoncause.org/site/pp.asp?c=dkLNK1MQIwG\&b=4773849.

Daniel, E. 2001. "Public Financing: Making it Work." League of Women Voters pp. 8-13.

Ensley, Michael J. 2009. "Individual Campaign Contributions and Candidate Ideology." Public

Choice 138(1): 221-238.

Francia, Peter L., and Paul S. Herrnson. 2003. "The Impact of Public Finance Laws on Fundraising in State Legislative Elections." American Politics Research 31(5): 520-539.

Gilens, Martin. 2012. Affluence \& Influence: Economic Inequality and Political Power in America. Princeton, NJ: Princeton University Press.

Gronke, Paul, Eva Galanes-Rosenbaum, Peter A. Miller, and Daniel Toffey. 2008. "Convenience Voting." Annual Review of Political Science 11(1): 437-455.

Hall, Andrew B. 2014. "How the Public Funding of Elections Increases Candidate Polarization." Paper presented at the annual meeting of the Southern Political Science Association, New Orleans, LA. 
Hall, Richard L, and Frank W. Wayman. 1990. "Buying Time: Moneyed Interests and the Mobilization of Bias in Congressional Committees." American Political Science Review 84(3): 797820.

Hamm, Keith E., and Robert E. Hogan. 2008. "Campaign Finance Laws and Candidacy Decisions in State Legislative Elections.” Political Research Quarterly 61(3): 458-467.

Hogan, Robert E. 2001. "Campaign War Chests and Challenger Emergence in State Legislative Elections." Political Research Quarterly 54(4): 815-830.

Hogan, Robert E. 2005. "State Campaign Finance Laws and Interest Group Electioneering Activities." Journal of Politics 67(3): 887-906.

Holland, Paul W. 1986. "Statistics and Causal Inference." Journal of the American Statistical Association 81(396): 945-960.

Keele, Luke, Neil Malhotra, and Colin H. McCubbins. 2013. "Do Term Limits Restrain State Fiscal Policy? Approaches for Causal Inference in Assessing the Effects of Legislative Institutions." Legislative Studies Quarterly 38(3): 291-326.

Klein, Ezra. 2013. "Big Money Corrupts Washington. Small Donors Polarize It." The Washington Post (Wonkblog). 10 May 2013. Retrieved January 9, 2015. http://www.washingtonpost.com/blogs/wonkblog/wp/2013/05/10/

big-money-corrupts-washington-small-donors-polarize-it/.

Krugman, Paul. 2002. “America The Polarized.” The New York Times. 4 January 2002. Retrieved January 9, 2015.

http://www.nytimes.com/2002/01/04/opinion/america-the-polarized.html.

La Raja, Raymond J. 2008. Small Change: Money, Political Parties, and Campaign Finance Reform. Ann Arbor, MI: University of Michigan Press.

La Raja, Raymond J., and David L. Wiltse. 2012. "Don't Blame Donors for Ideological Polarization of Political Parties: Ideological Change and Stability Among Political Contributors, 1972-2008." American Politics Research 40(3): 501-530.

Malhotra, Neil. 2008. "The Impact of Public Financing on Electoral Competition: Evidence from Arizona and Maine.” State Politics \& Policy Quarterly 8(3): 263-281.

Martin, Andrew D., and Kevin M. Quinn. 2002. "Dynamic Ideal Point Estimation via Markov Chain Monte Carlo for the U.S. Supreme Court, 1953-1999.” Political Analysis 10(2): 134-153. Masket, Seth E., and Michael G. Miller. 2015. "Does Public Election Funding Create More Extreme Legislators? Evidence from Arizona and Maine." Forthcoming, State Politics \& Policy Quarterly.

Mayer, Kenneth R. 2013. "Public Election Funding: An Assessment of What We Would Like to Know." The Forum 11(3): 365-384.

McCarty, Nolan. 2014. "What We Know and Don't Know About our Polarized Politics." The Washington Post (The Monkey Cage). 8 January 2014. Retrieved January 9, 2015.

http://www.washingtonpost.com/blogs/monkey-cage/wp/2014/01/08/

what-we-know-and-dont-know-about-our-polarized-politics/.

McCarty, Nolan, Keith T. Poole, and Howard Rosenthal. 2006. Polarized America: The Dance of Ideology and Unequal Riches. Cambridge, MA: The MIT Press.

Miler, Kristina C. 2010. Constituency Representation in Congress: The View from Capitol Hill. New York: Cambridge University Press.

Morehouse, Sarah M., and Malcolm E. Jewell. 2004. "States as Laboratories: A Reprise." Annual Review of Political Science 7(1): 177-203. 
Morgan, Stephen L., and Christopher Winship. 2007. Counterfactuals and Causal Inference: Methods and Principles For Social Research. New York: Cambridge University Press.

Powell, Lynda W. 2012. The Influence of Campaign Contributions in State Legislatures: The Effects of Institutions and Politics. University of Michigan Press.

Primo, David M., and Jeffrey Milyo. 2006. "Campaign Finance Laws and Political Efficacy: Evidence from the States." Election Law Journal 5(1): 23-39.

Rainey, Carlisle. 2014. "Arguing for a Negligible Effect." American Journal of Political Science 58(4): 1083-1091.

Schattschneider, E. E. 1960. The Semisovereign People: A Realist's View of Democracy in America. New York: Holt, Rinehart, and Winston.

Schlozman, Kay Lehman, Sidney Verba, and Henry E. Brady. 2012. The Unheavenly Chorus: Unequal Political Voice and the Broken Promise of American Democracy. Princeton, NJ: Princeton University Press.

Shor, Boris, and Nolan McCarty. 2011. "The Ideological Mapping of American Legislatures." American Political Science Review 105(3): 530-551.

Squire, Peverill. 2007. "Measuring Legislative Professionalism: The Squire Index Revisited." State Politics \& Policy Quarterly 7(2): 211-227.

Stone, Walter J., and Elizabeth N. Simas. 2010. "Candidate Valence and Ideological Positions in U.S. House Elections.” American Journal of Political Science 54(2): 371-388.

Stratmann, Thomas. 1992. "Are Contributors Rational? Untangling Strategies of Political Action Committees." Journal of Political Economy 100(3): 647-664.

Stratmann, Thomas. 2005. "Some Talk: Money in Politics. A (Partial) Review of the Literature." In Policy Challenges and Political Responses, ed. William F. Shughart, and Robert D. Tollison. New York: Springer pp. 135-156.

Stratmann, Thomas. 2006. "Is Spending More Potent For or Against a Proposition? Evidence from Ballot Measures.” American Journal of Political Science 50(3): 788-801.

Stratmann, Thomas, and Francisco J. Aparicio-Castillo. 2006. "Competition Policy for Elections: Do Campaign Contribution Limits Matter?” Public Chocie 127(1-2): 177-206.

Wawro, Gregory. 2001. "A Panel Probit Analysis of Campaign Contributions and Roll-Call Votes." American Journal of Political Science 45(3): 563-579.

Witko, Christopher. 2006. "PACs, Issue Context, and Congressional Decisionmaking." Political Research Quarterly 59(2): 283-295. 
Figure 1: The Effect of Public Financing in 2005 on the Extremity of New Jersey Assemblymembers' Ideal Points

(a) Louis D. Greenwald, Committee Votes

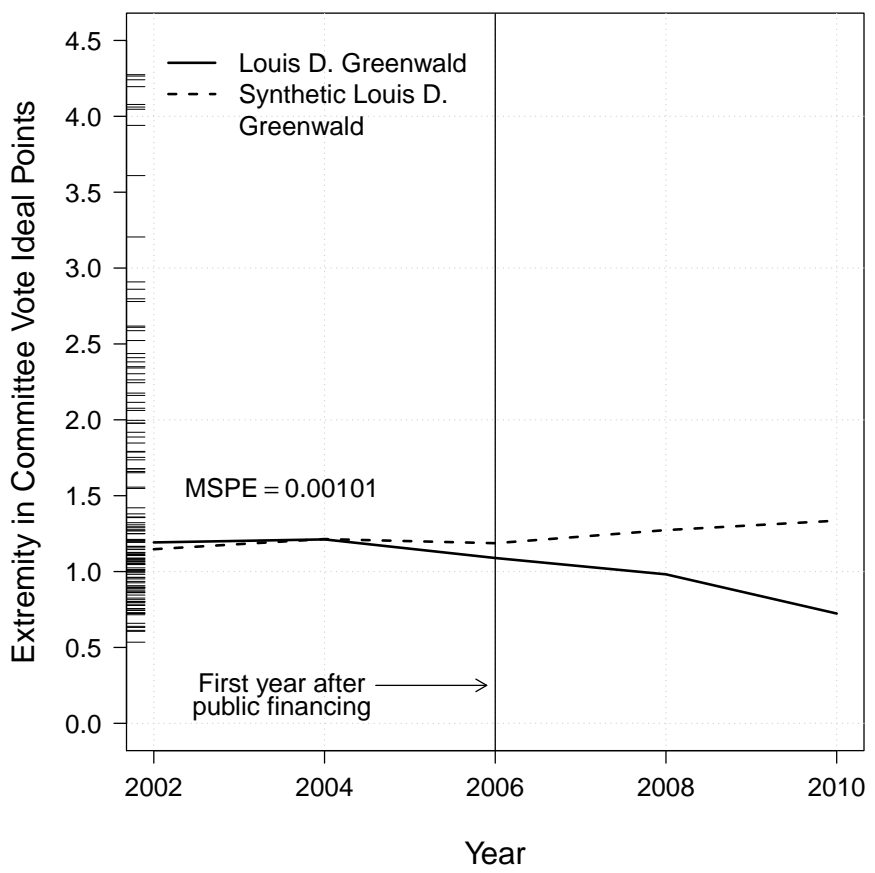

(c) Samuel D. Thompson, Committee Votes

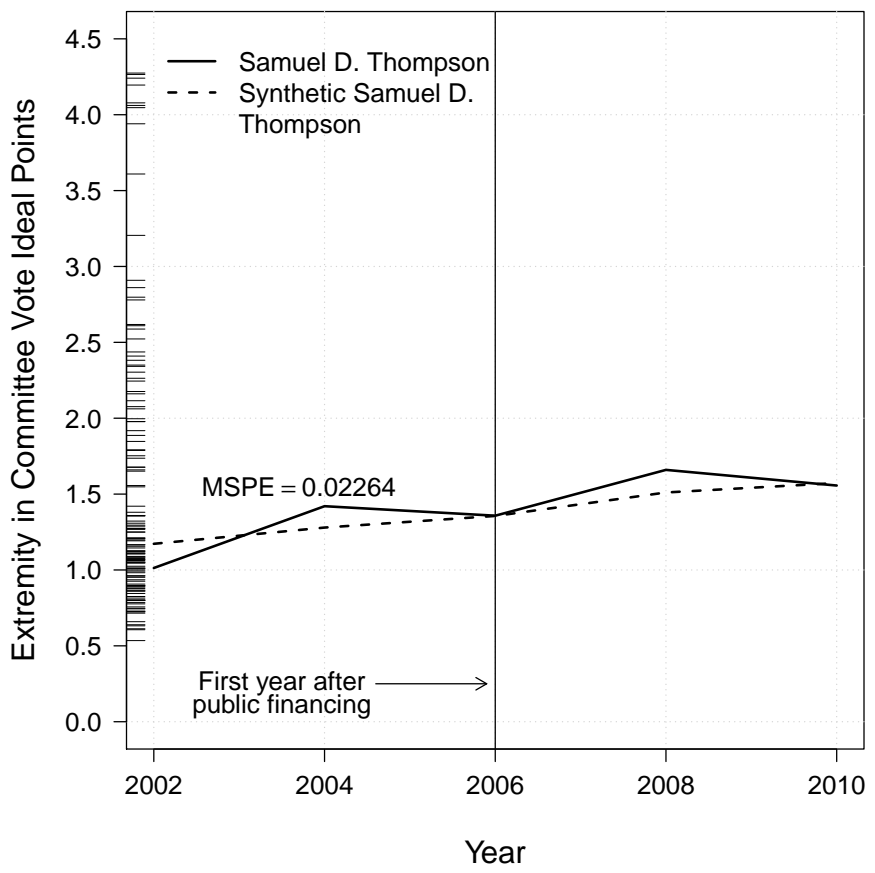

(b) Louis D. Greenwald, Floor Votes

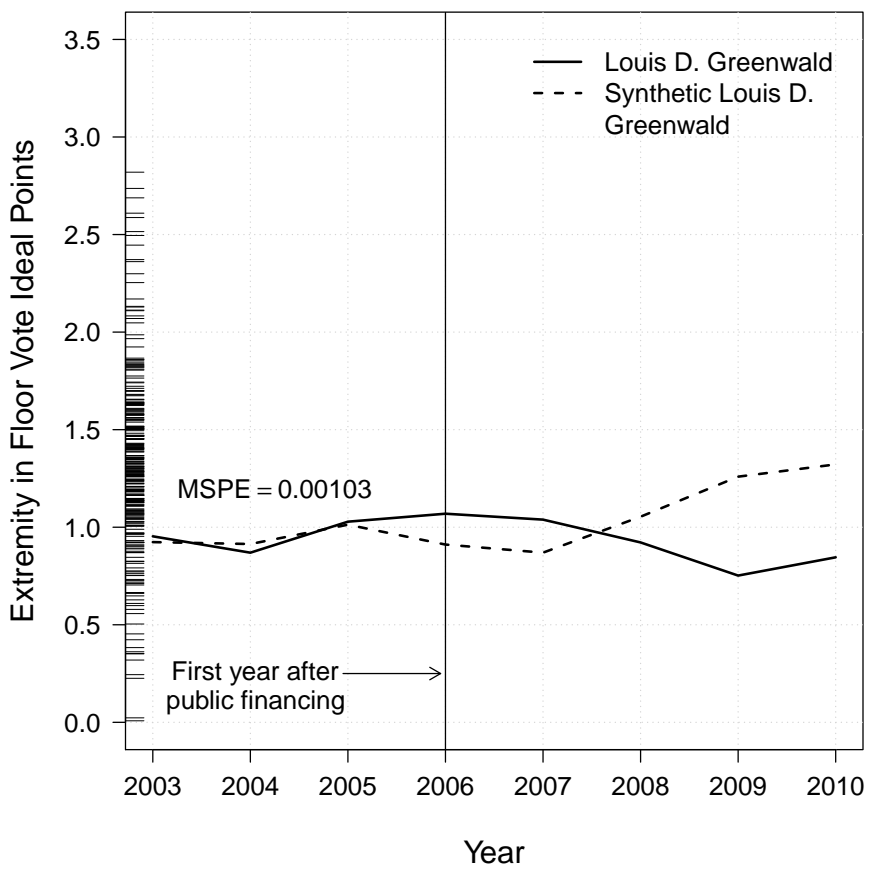

(d) Samuel D. Thompson, Floor Votes

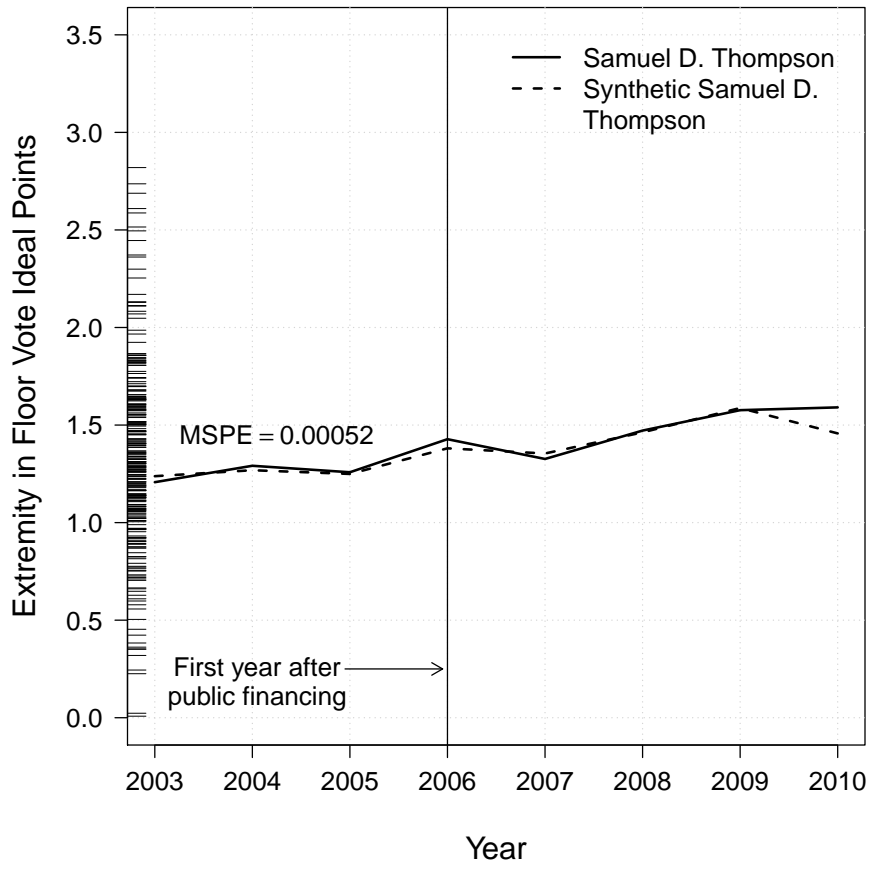

Note: The graphs present the extremity of each legislator's ideal points (solid lines) and the synthetic case predictions (dashed lines) before and after taking public financing. Panels (a) and (c) present extremity in committee vote ideal points and panels (b) and (d) present extremity in floor vote ideal points. MSPE measures the amount of error between the actual outcome of the treated legislator and the synthetic case's predicted outcome before the intervention of public financing (see Abadie, Diamond, and Hainmueller 2010). 


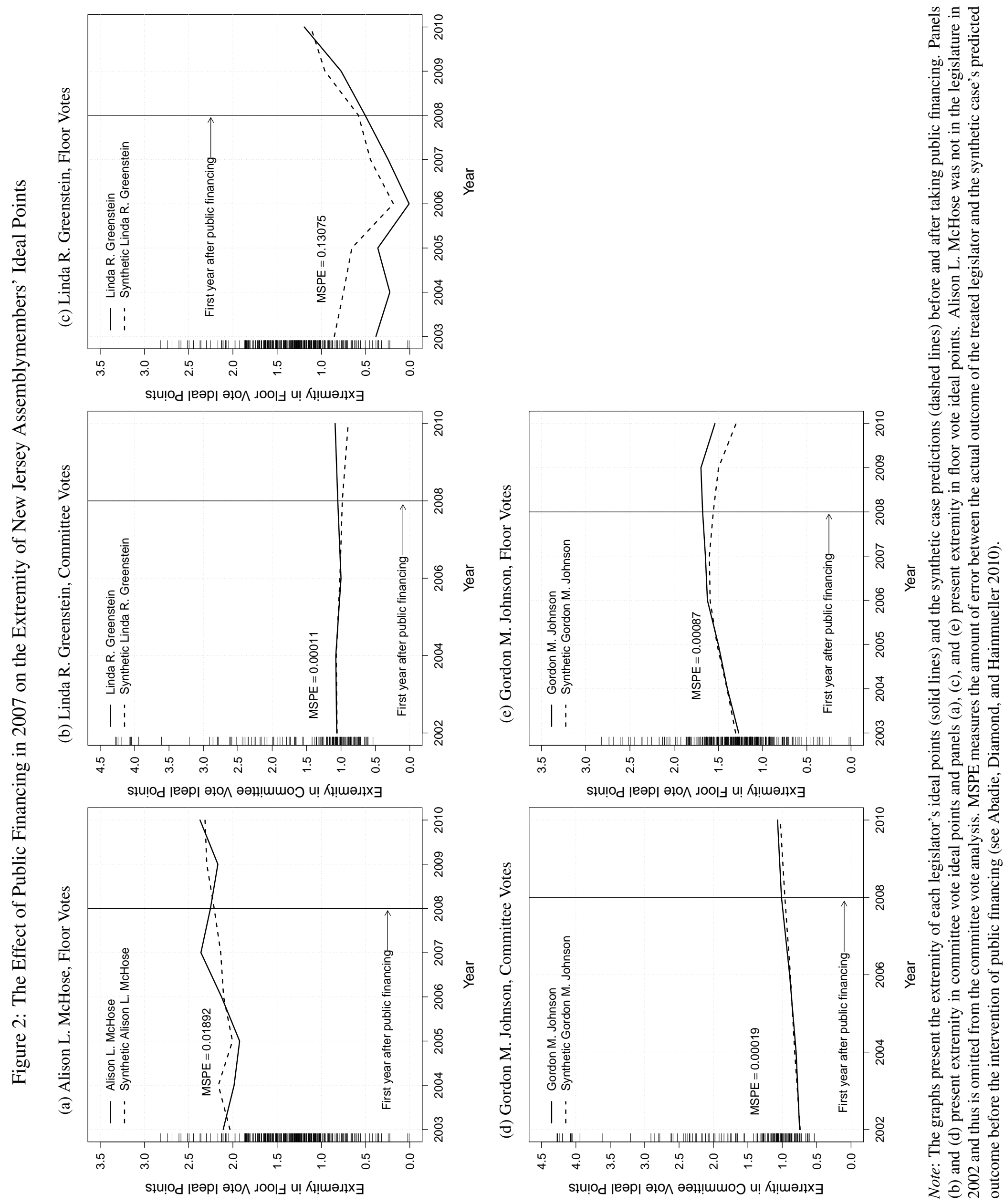




\section{Figure 3: Publicly-Financed Legislators Gaps Analyses with Placebo Tests on Control Legislators}

(a) Committee Votes

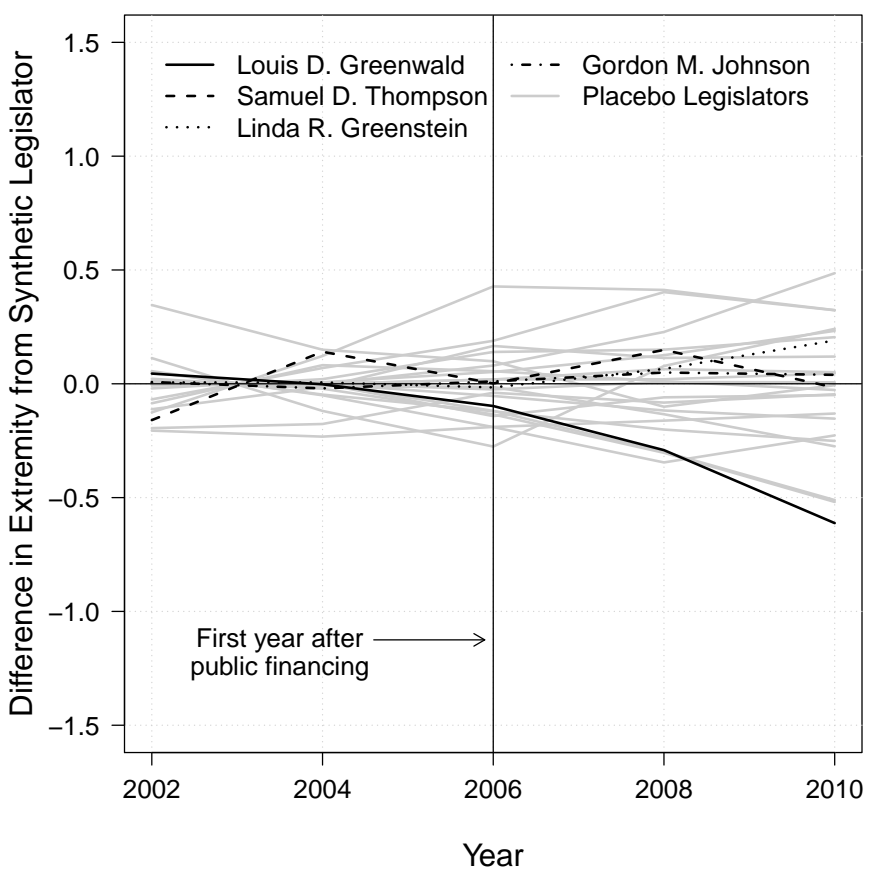

(b) Floor Votes

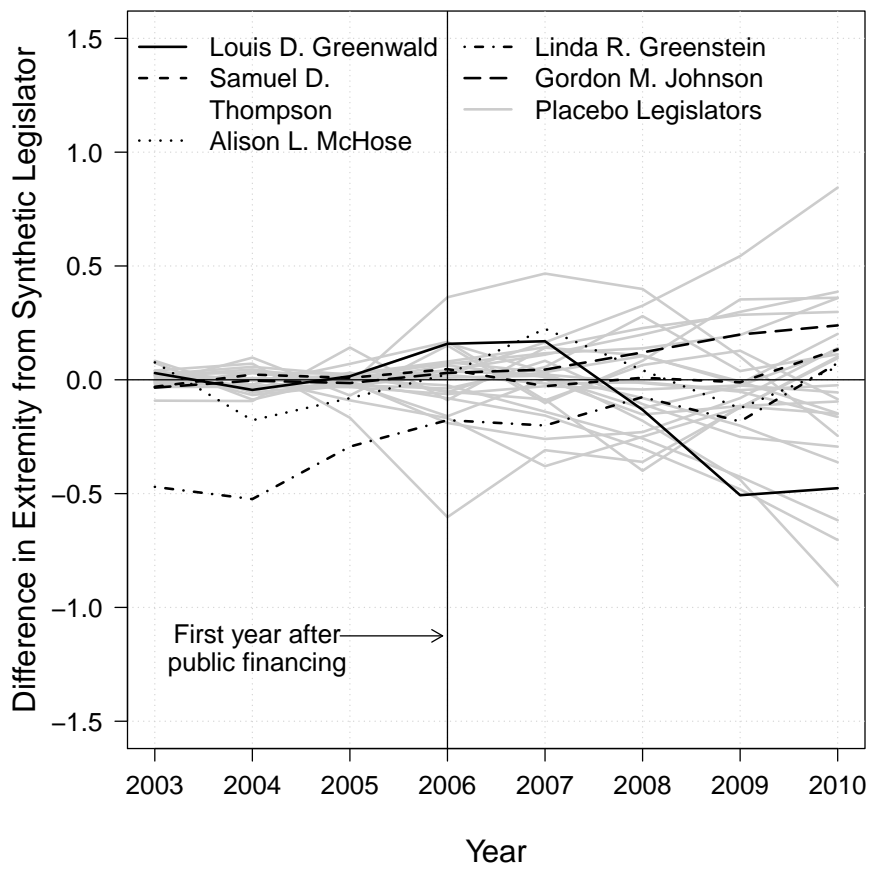

Note: The graphs present gaps analyses for committee vote ideal points (panel a) and floor vote ideal points (panel b). Each line represents the difference between the actual extremity of a legislator's roll-call voting behavior and his or her synthetic case's prediction. Black lines denote legislators who took public financing and gray lines denote control legislators who did not participate (placebo tests). 
Figure 4: The Effect of Public Financing in 2000 on Polarization in the Arizona and Maine Legislatures

(a) Arizona

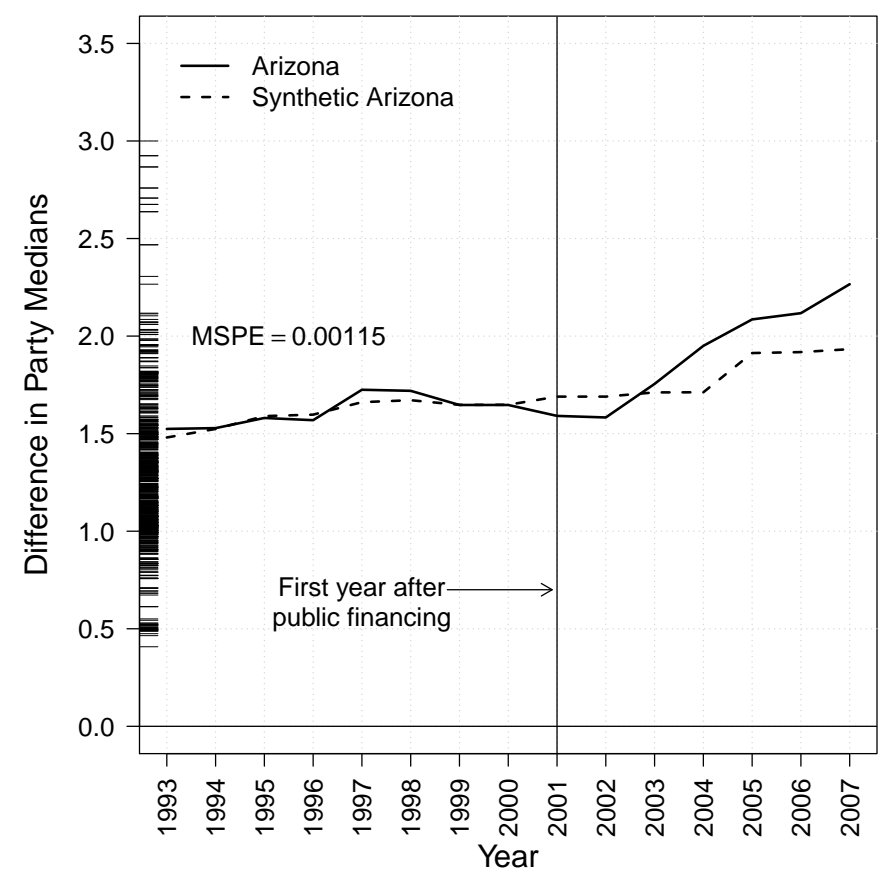

(b) Maine

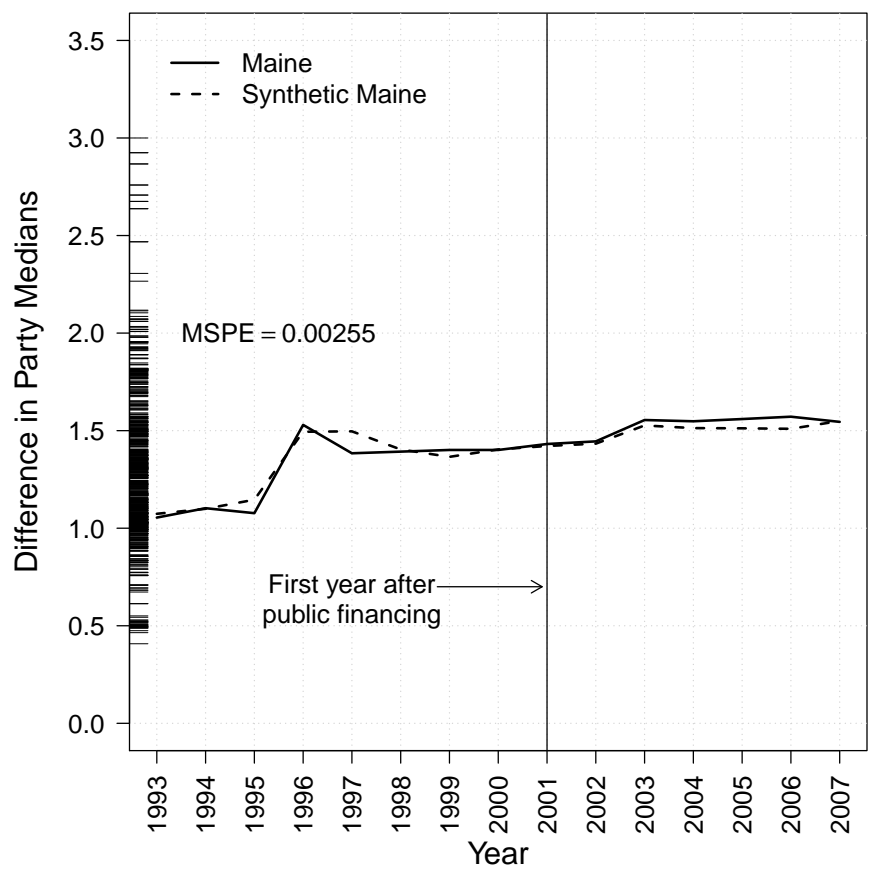

Note: The graphs present the difference in party medians (solid lines) and the synthetic case predictions (dashed lines) before and after the implementation of public financing in Arizona (panel a) and Maine (panel b). MSPE measures the amount of error between the actual outcome of each state and the synthetic case's predicted outcome before the intervention of public financing (see Abadie, Diamond, and Hainmueller 2010). 
Figure 5: Public Finance States Gaps Analysis with Placebo Tests on Control States

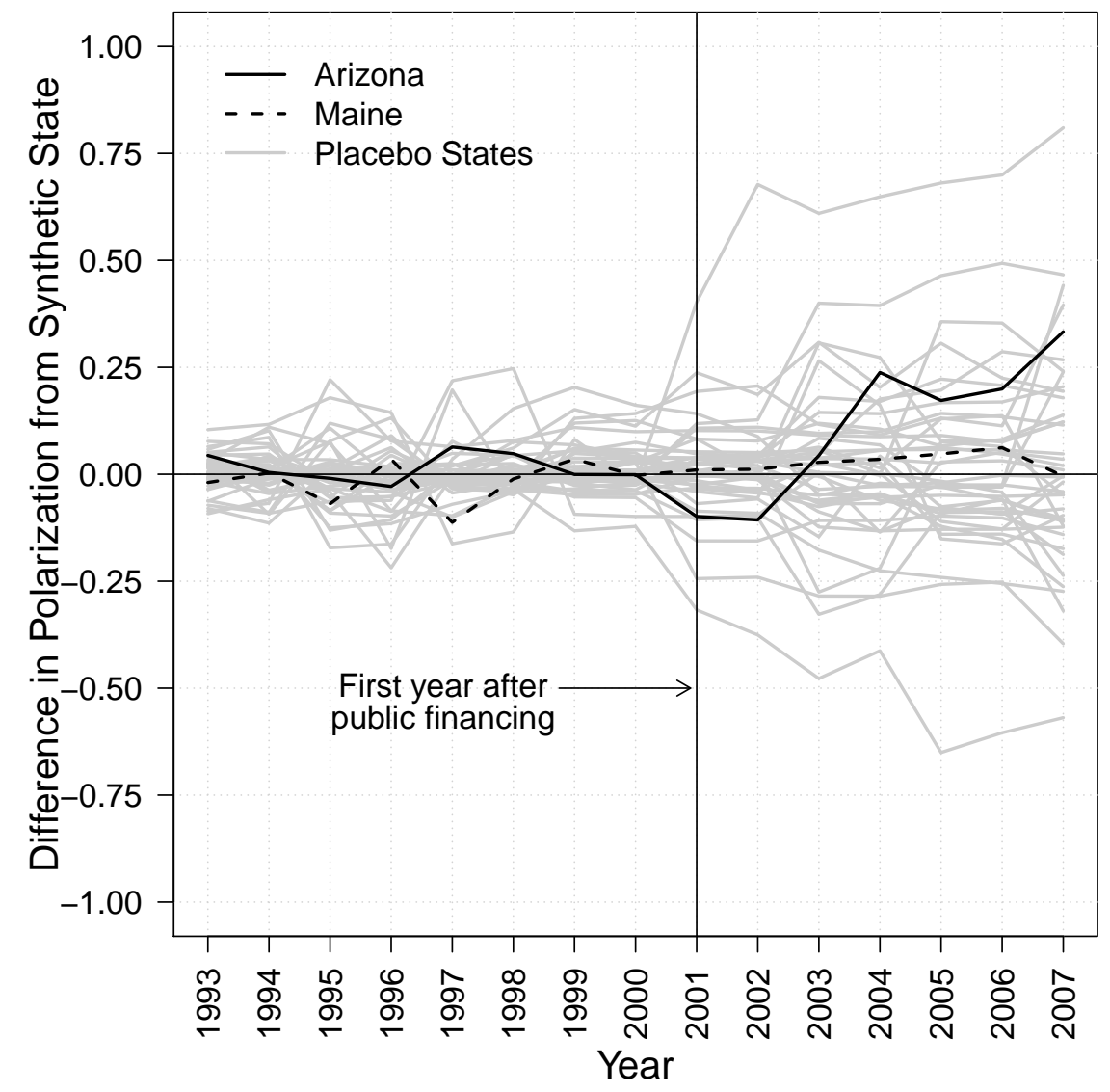

Note: The graph presents gaps analysis for differences in party medians. Each line represents the difference between the actual difference in party medians in a state and its synthetic case's prediction. Black lines denote Arizona and Maine and gray lines denote control states who did not adopt public financing (placebo tests). 
Table 1: Summary of the Synthetic Case Control Results

\begin{tabular}{lrrrrr}
\hline Name & Votes & Year & Effect & $p$ & MSPE \\
\hline Louis D. Greenwald & Committee & 2005 & -0.19 & 0.38 & 0.001 \\
Louis D. Greenwald & Floor & 2005 & -0.10 & 0.21 & 0.001 \\
Samuel D. Thompson & Committee & 2005 & +0.02 & 0.73 & 0.02 \\
Samuel D. Thompson & Floor & 2005 & +0.02 & 0.55 & 0.0005 \\
Alison L. McHose & Floor & 2007 & +0.005 & 0.85 & 0.02 \\
Linda R. Greenstein & Committee & 2007 & +0.05 & 0.38 & 0.0001 \\
Linda R. Greenstein & Floor & 2007 & -0.23 & 0.85 & 0.13 \\
Gordon M. Johnson & Committee & 2007 & +0.02 & 0.54 & 0.0002 \\
Gordon M. Johnson & Floor & 2007 & +0.07 & 0.33 & 0.0009 \\
Means & - & - & -0.04 & 0.54 & 0.02 \\
\hline Arizona & Floor & 2000 & +0.06 & 0.41 & 0.001 \\
Maine & Floor & 2000 & +0.003 & 0.24 & 0.003 \\
Means & - & - & +0.03 & 0.33 & 0.002 \\
\hline
\end{tabular}

Cell entries report a summary of the synthetic case control results. The top portion gives results for the New Jersey assemblymembers and the bottom portion gives results for the Arizona and Maine legislatures. The second column labels the voting source for the ideal points and the third column lists the public financing year. The fourth column gives the mean difference in the outcome (ideal point extremity for the New Jersey assemblymembers, polarization for Arizona and Maine) between the actual and synthetic case after public financing (positive values indicate an increase in extremity or polarization and negative values indicate a decrease). The fifth column gives the $p$-value for the effect, computed from the placebo tests. The final column gives the pre-treatment MSPE values. The rows labeled "Means" give the mean of each column within each portion of the table. 